\title{
YENISEY YAZITLARI ARASINDA BİR ÇİN AYNASI: E 77
}

\section{Tuba YALINKILIÇ*}

Öz

Yenisey mezar yazıtları arasında, üzerinde kimi zaman runik harfli Köktürkçe ve Çince yazılı kimi zaman yazısız fakat yine Çin tarzında aynalar karşımıza çıkmaktadır. Üzerinde bulunan metin veya motiflerle, ait olduğu dönemin özelliklerini yansıtan bu aynalar, çoğu zaman da iki ülke arasında kurulan ilişki ve ticari alışverişler adına çalışmalarımıza ışık tutmaktadır. Yenisey yazıtları arasında yer alan aynaların benzer birçok örneği bugün Çin'deki müzelerde muhafaza edilmekte veya sergilenmektedir. Çalışmada bu aynalardan 77 Numaralı Ayna II'nin hikâyesi ve birtakım özellikleri ele alınmıştır.

Anahtar Sözcükler: Türk yazıtları, Yenisey Yazıtları, Çince yazılı Yenisey Yazıtları, Çin aynaları, Konfüçyüs.

\section{A CHINESE MIRROR AMONG THE YENISEI INSCRIPTIONS: E 77}

\section{Abstract}

We can see some inscriptions in Kokturk with runic letter or Chinese texts, also sometimes without any texts on but emerges in the style of Chinese mirrors among Yenisei Inscriptions. These mirrors which reflect the characteristic of their period with the texts and motifs on them, usually illuminate the relations and trade between two countries as well. Many examples of mirrors that located among Yenisei inscriptions are being kept or exhibited in museums in China. You can find the story and some features of 77 Numbered Mirror II in this article.

Keywords: Turkic inscriptions, Yenisei Inscriptions, Yenisei Inscriptions in Chinese, Chinese mirrors, Confucius.

\section{Ø. Giriş:}

Dünya tarihinde aynalar, doğu ve batı medeniyeti eserleri olarak iki grupta incelenmektedir. Batı grubu altında Yunan, Misır, Roma $v b$. medeniyetlerin eserleri ele alınır. Bugün yalnızca eski dönemin endüstriyel ürünü olarak algılanan Çin eski bronz aynalarıysa Çin kültür ve medeniyetinin ayrılmaz unsurlarından olup muhteşem sanat örnekleridir. Esasen aksesuar olan aynalar, arka yüzlerinde barındırdığg motif, yazı, metin vs. aracılığıyla tarihî dönem ve toplumsal düşünceler adına bize bilgi verir.

Yaklaşık dört bin yıllık bir döneme yayılmış olan aynalar bulundukları dönemin, kendine ait özelliklerini yansıtmaktadır. Biçim açısından bakıldığında, kare, çiçek biçimli, kılıflı vs. aynalar olarak ayrılırken, daire biçimli ve düğmeli aynalara her dönemde rastlanmaktadır. Hatta diğer medeniyet kalıntılarında pek de izine rastlanmayan kare, çiçek $v b$. formda aynalar karakteristik Çin aynalarıdır.

\footnotetext{
* Doktora Öğrencisi; Pekin Üniversitesi, Tarih Fakültesi, Eski Çin Tarihi, yalinkilictugba@ hotmail.com.
} 
Bronz aynaların tarih sahnesine çıkışından evvel belli bir gelişim süreci yaşanmıştır. $\mathrm{Bu}$ dönemi akademisyenler Çin için beşe ayırır:

- Doğal ortamda bulunan suların kullanımı,

- Suların kap içinde kullanımı,

- Yine, kapların kullanıldığı süreçle eş zamanlı olarak, bıçak vs. gereçlerden yararlanarak bronz aynanın icadı sürecine girilmesi,

- Bronz aynanın icadı fakat kullanımının yaygın olmaması,

- Nihayet, bronz ayna kullanımının yaygınlaşması.

Çin'de bronz aynalar arasında Wei (386-557), Sui (581-618) ve Tang Hanedanlığı (618907) aynaları içerik ve özellik bakımından diğerlerinden ayrılmaktadır. Bilhassa, Tang Hanedanlığı Dönemi’nde iktisadi ve kültürel anlamda kazanılan gelişim, sanat alanına da yansımıştır. Bu gelişimlerin takip etmiş olduğu, yabancılarla olan ticari alışverişin neticesinde de birçok ürünün Çin dışına taşınma imkânı olmuştur.

Eski Çin'de hediye niteliği taşıyan bronz aynalar, sanat ve edebiyat açısından zamanla değişime uğradığı için, konunun uzmanları, bu aynaları dönemlerine göre sınıflandırmayı tercih etmişlerdir. Sui ve Tang aynaları,

Sui Hanedanlı̆̆ı'ndan Tang Gaozong'a kadar olan ilk dönem (581-628),

Tang Gaozong'dan Tang Dezong'a kadar olan ikinci dönem (628-742),

Tang Dezong'dan Geç Tang Dönemi’ne (742-907) kadar olan son dönem olmak üzere üç büyük döneme ayrılarak incelenir.

Tang Hanedanlı̆̆ı'na ait,

Dört kutsal ve 12 hayvanlı ayna,

Dört kutsal aynas1,

Çiçek biçimli ayna,

Çiçek ve kelebek biçimli ayna,

Karmaşık çiçek motifli ayna,

Ölümsüz şahsiyetlerin hikâyesinin aynası gibi aynalar bulunmaktadır. İçlerinden "Üç Mutluluk Aynası”, “Ölümsüz Şahsiyetlerin Hikâyesi” aynası türündendir. Bu ayna, Konfüçyüs 
figürü taşıması hasebiyle türünün tek örneğidir. ${ }^{1}$ Aynı zamanda Tang Hanedanlığı dönemine ait, Taoizm öğretisini sergiler niteliktedir.

\section{Yenisey Yazıtları Arasında Çin Aynaları ve E 77 Ayna II:}

Yenisey Yazıtları arasında dokuz adet Çin aynası bulunmakla birlikte bunların çoğunluğu ayna parçası şeklindedir (E76, E77, E84, E85, E128, E129, E130, E143). Bu aynaların, yazı olan yüzeylerinin zaman içerisinde tahrip olmuş olmasından ötürü, okunabildiği kadarıyla, eğer bir hikâye teması içeriyorsa bu hikâyeye ulaşmaya; böyle bir yazı izi veya kalıntısı yoksa, aynanın biçim özelliklerinden hangi döneme ait olduğunu bulmaya çalışabiliriz.

$\mathrm{Bu}$ yazıtlar arasında yer alan 77 numaralı Ayna II aynı zamanda Zerkalo II olarak da adlandırılır ve büyük oranda tahrip olmuş aynalardandır. Elimizde söz konusu aynanın yarısından daha küçük diyebileceğimiz bir kısmı vardır. Ne var ki bugüne kadar sağlam kalmış bu kısımda Çince metnin hepsi net olarak okunabilmektedir. Bu da bizim, aynanın tanımını yapabilmemiz adına işimizi son derece kolaylaştırmaktadır.

Bununla birlikte, aynanın üzerinde 16 harften oluşan Köktürkçe metin vardır:

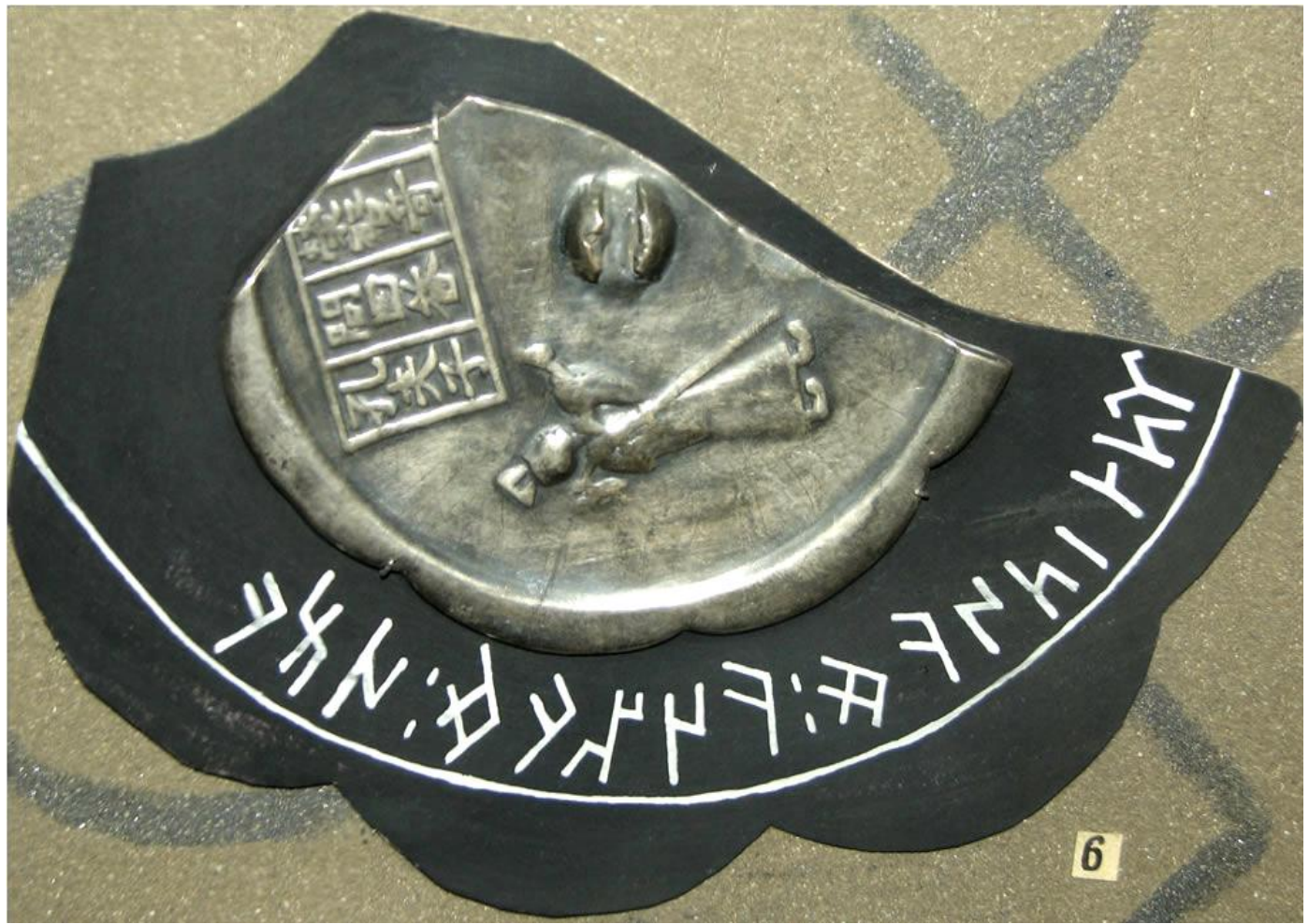

E 77 Ayna II'nin Köktürkçe metninin görüntüsü²

\footnotetext{
${ }^{1}$ HUAITONG, L. ve YUHAO, L. (2010). Çin Bronz Aynaları Tarihi. Zhongzhou Guji Basımevi. s. 214.

${ }^{2}$ http://bitig.org/show_big.php?fn=sizes/2580.jpg 03.10.2015.
} 


\section{Yazı Çevirimi:}

er <atım> ten tükemiş közyüm üzk ${ }^{2}$

\section{Metnin Türkçeye Çevirisi:}

Erkeklik adım Teng Tükemiş('tir). Aynam $<\ldots>^{3}$

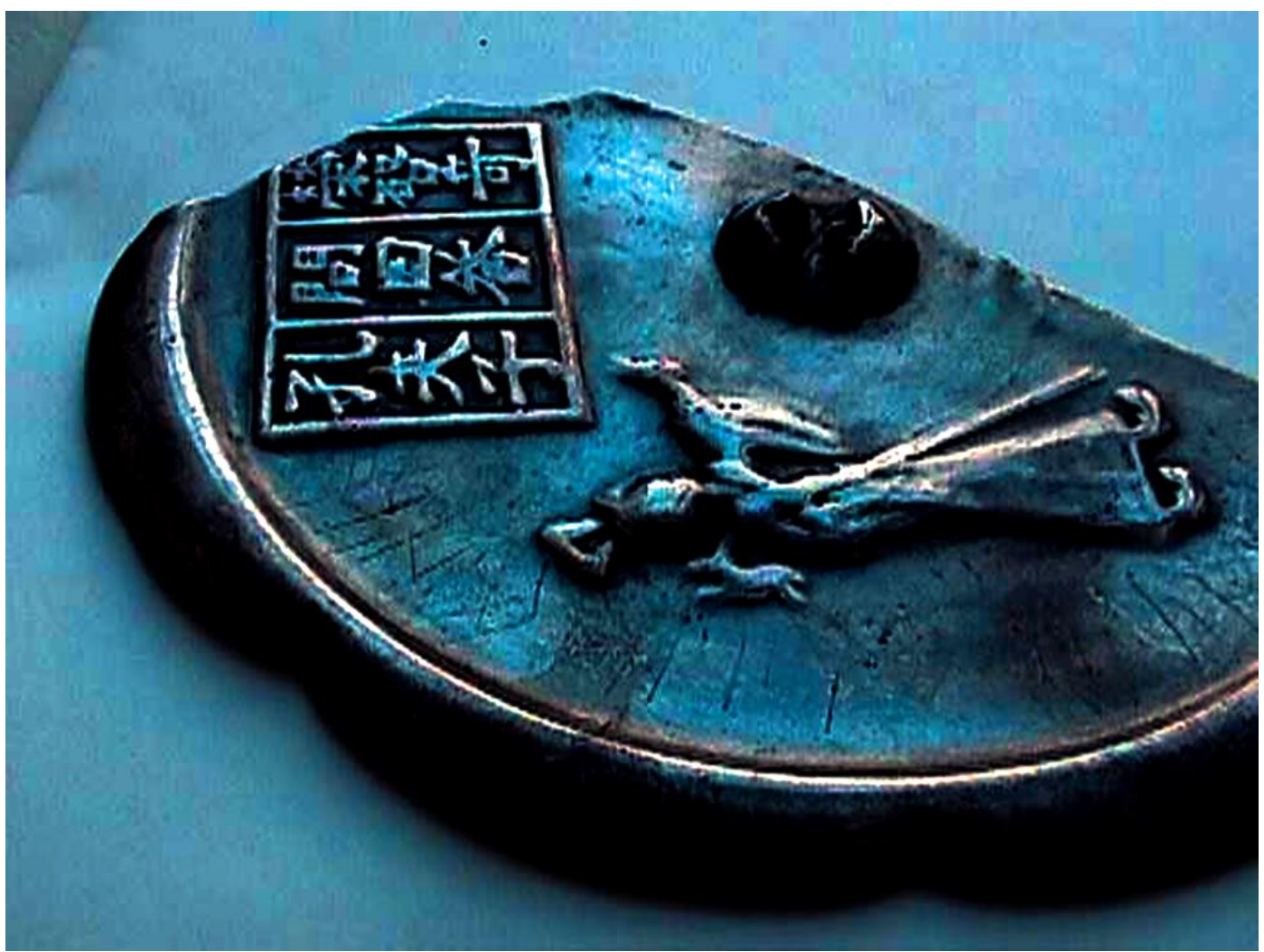

E 77 Ayna II'nin sağlam kalan kismının bir görüntüsü ${ }^{4}$

Ayna II'nin önemli bir kısmı kırılmış olmasına rağmen, sağlam kalan parçanın üzerinde, dokuz karakterden oluşan荣启奇问曰答孔夫子 Rong Qiqi ve Konfüçyüs’ün mütalaası yazısı bize, aynanın Tang Hanedanlığı tarzında olan 荣启奇葵花镜 Rong Qiqi, ay çiçek biçimli ayna olduğunun ipucunu vermektedir. Aynanın diğer bir adı da “Üç Mutluluk Aynası”dır.

\footnotetext{
${ }^{3}$ YILDIRIM, F., AYDIN, E. ve ALIMOV, R. (2013). Yenisey-Kırgızistan Yazıtları ve Irk Bitig. Ankara: Bilgesu. s. 165.

${ }^{4}$ http://bitig.org/?m=2\&oid=63\&mod=1\&tid=2\&lang=k 29.05.2015.
} 


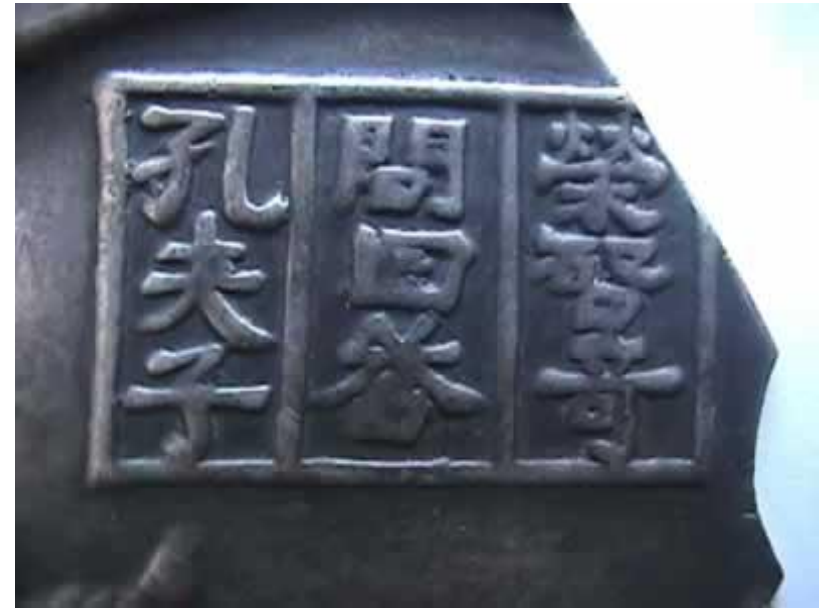

E 77 Ayna II'nin üzerinde bulunan Çince metnin görüntüsüَ

Mezarlarda bulunan Üç Mutluluk Aynası diğerlerinden farklı olarak, Çin'deki bir kıssanın vücut bulduğu bir eserdir. Ayna, üzerinde insan figürünün resmedilmesi açısından da dönemine ait özel tasarımda bir eserdir.

Söz konusu aynanın diğer örneklerini bugün, Luo Yang Müzesine ait Luo Yang'da Çıkarılan Bronz Aynalar adlı eserde bulmak mümkündür.

Aynanın mahiyetini tam olarak görebilmek adına, bugün onlarca bulunan örneklerinden biri şöyledir:

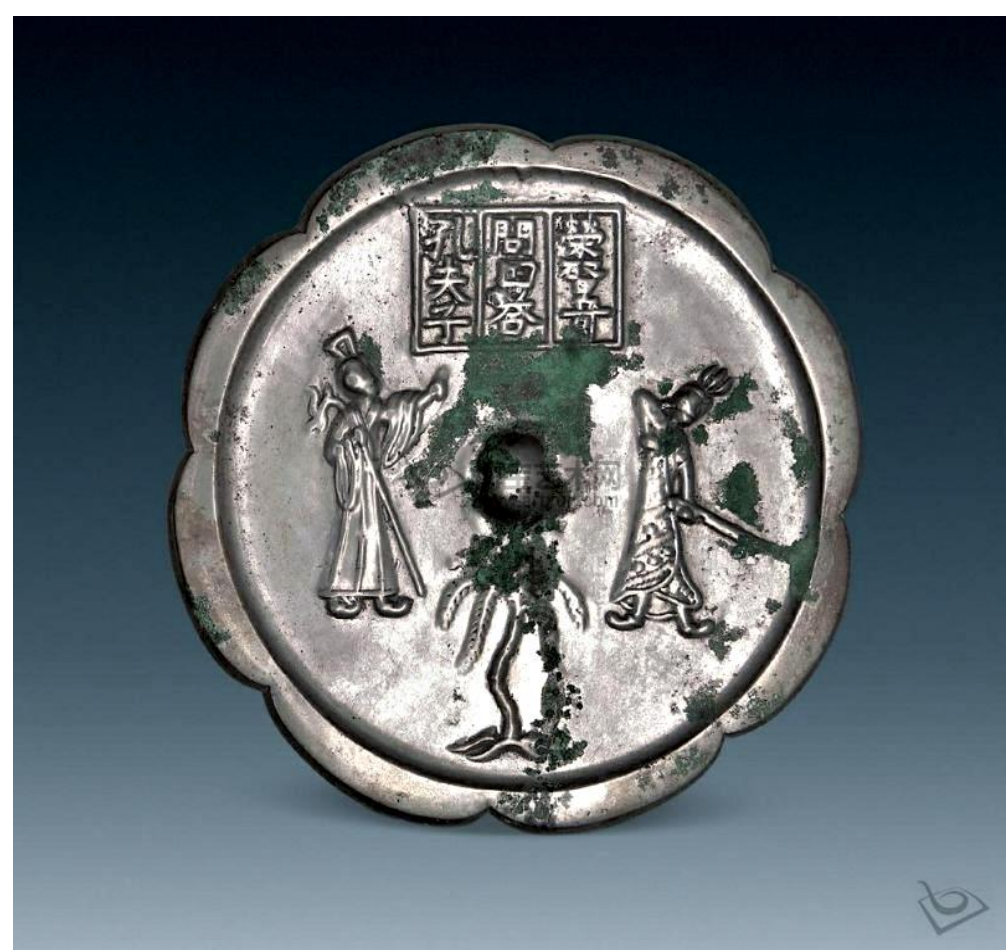

Tang Hanedanlığı'na ait “ $\ddot{U c ̧ ~ M u t l u l u k ~ A y n a ~ Y a z ı t ı ” ~ o ̈ r n e g ̆ i ~}{ }^{6}$

${ }^{5}$ http://bitig.org/?m=2\&oid=63\&mod=1 $\&$ tid=2\&lang=k 29.05.2015.

TFरP 
Aynanın tam görüntüsünün sol tarafında, üzerinde bol ve uzun kollu cübbesi, başında başlığıyla, sağ kolu içe doğru kıvrılmış, sol elinin iki parmağını kaldırmış olan Konfüçyüs, soru sorar vaziyettedir. Ayna üzerindeki görüntüde sağ tarafta başında, kürk aksesuarla süslenmiş başlı̆̆ıyla, sol elinde müzikal enstrümanla, müzik yapıp şarkı söyleyen keşiş 荣启奇 Rong Qiqi bulunmaktadır. Aynanın kulpu veya düğmesi olarak adlandırabileceğimiz orta kısmı üzerindeyse bir söğüt ağacı yer almaktadır. Söğüt ağacının olması, mekânın, yerleşim yerinde olduğunu göstermektedir. Bu türden bir motife sahip olan ayna 三乐镜 “Üç Mutluluk Aynası” olarak da adlandırılır. ${ }^{7}$

Aynanın bir diğer özelliği ise kendine has bir hikâyeye sahip olmasıdır. Bu hikâye, Savaş Ülkeleri Dönemi'nde yaşamış olan, Taoizm temsilcisi düşünür 列御寇 Lie Yukou'un 列子·天瑞 Liezi eserinin Tianrui bölümünde bulunmaktadır. Düşünür, 571-474 yılları arasında yaşamış olan keşişlerden Rong Qiqi ile Konfüçyüs arasında geçen konuşmayı aktarmaktadır:

Konfüçyüs, Tai Dağı'nda gezindiği bir gün, şehrin tarlalarında dolaşmakta olan Rong Qiqi ile karşılaşır. Rong Qiqi koluna aldığı heybeyle, kanun çalıp, şarkı söylemektedir. Konfüçyüs sorar:

\section{- Neden bu kadar mutlusun?}

Rong Qiqi cevaben:

- Mutluluğumun birçok sebebi var, yer gök nimetlerle dolu, insan değerli bir varlık ve ben de bir insanım, nedenlerden ilki budur. Erkek ve kadın olarak iki ayrı cins var, erkek saygl duyar, kadın hürmet eder, eskiden beri erkek değerlidir ve ben de bir erkeğim, bu ikinci mutluluk nedenim. Gün görmeden ölen bebekler var, bense 90 yaşındayım, bu kadar uzun yaşamış olmam da üçüncü mutluluk nedenim. Yoksulluğa gelince, o da insanlığın sıradan durumlarından biri, ölüm herkesin varacağı son durağı. Benim yoksulluğum insanlı̆̆ın yaşayageldiği bir şey, ihtiyar birinin ölümü de olağandir, endişe etmeyi gerektirecek ne var ki? der. Konfüçyüs ise:

- Sen kendi kendini teselli eden, sıkıntıları büyütmeyen gerçek bir bilgesin! Sözleriyle övgüsünü dile getirir.

\section{2. Çin Aynalarının Diğer Bölgelere Geçişi:}

Çin'in yabancı bölgelerle olan ticari tarihi içerisinde bronz aynalar önemli bir yer teşkil eder. Çin eski aynaları, bilhassa Han - Tang Dönemi aynaları, İpek Yolu ticareti vasıtasıyla batı bölgelerine taşınmıştır. Sui ve Tang Handanlığı dönemlerine ait bronz aynalara İpek Yolu

\footnotetext{
${ }^{6}$ http://auction.artxun.com/pic-10014569-0.html 29.05.2015.

7 YUKOU, L. (2008). Liezi Tianrui. Zhonghua Kitabevi. s. 3.
} 
üzerinde de rastlanılmıştır. En fazla örnekleri de üzüm motifli bronz ayna ve Qin Kralı Yazıtı metinli erken dönem Tang Hanedanlığı aynası, prizma ayna, dört kuş motifli ayna, üç mutluluk aynası, buket çiçek aynası, köşeli ayna $v b$. dökme bronz aynalarıdır.

Tang Hanedanlığı Dönemi'nde, imparatorun "bayram" olarak addedilen doğum gününde kutlamalar ve hediyeler kabul edilirdi. Yine, dönemin "Rong Qiqi ve Konfüçyüs" aynası, kaderin sunduklarına razı olma anlayışını yansıtır niteliktedir. ${ }^{8}$

Üç mutluluk teması, Tang Dönemi hikâyeleri arasında son derece meşhur olup, bu dönemin düşünce yapısının saraydan halka yayılışını, hayatın Konfüçyanizm düşünce ve davranışlarıyla tefekkürünü yansıtır niteliktedir. Orta Çağ'da bronz aynalar, insanlar arasında hediye niteliğinde bir üründü, öyle ki yalnızca sarayda veya halk arasında değil, yine yabancı ülke elçilerine sunulan hediyeler arasındaydı. 三国 San Guo döneminde bronz aynalar, Çin ile yabancı ülkelerin ilişkilerini kuvvetlendirmek adına birer dostluk elçisi hükmündeydi. ${ }^{9}$

Sekizinci yüzyıl ortalarında, Orta Asya'daki bazı ülkeler Tang Hanedanlığı ile saray ziyaretleri dolayısıyla olan ilişkilerini devam ettirmekteydi. Bu dönemde Orta Asya'dan Çin'e gelenlerin sayısı bir hayli çoktu, öyle ki kimileri uzun süreliğine gelip yerleşir, hatta Tang Hanedanlığı'nda görev alırlardı. Bu kişiler Tang Hanedanlığı ve batı ülkeleri arasında kültürel ilişkiyi sağlamakta önemli rol oynardı. Bu kültürel alışveriş esnasında da Çin'den büyük oranda ipek, seramik, kağıt, çay ve demir gereçler Orta Asya ülkelerine taşınırdı. Daha evvel (Tang Hanedanlığı zamanında Kang ülke sınırları içinde yer alan) Semerkand'da Tang Dönemi'ne ait bronz ayna, bronz para, ipek dokuma ürünler vs. bulunduğu ${ }^{10}$ gibi, yine Yenisey mezar yazıtları arasında da Tang Hanedanlığı bronz aynalarına rastlanmış bulunmaktadır.

Sonuç olarak, kültürel ve ticari alışverişin bu denli canlı olduğu, diğer ülke temsilcileri veya elçilerinin düzenli olarak Çin ülkesine ziyarete geldiği dönemde, bugün bizlere Yenisey Yazıtları gibi değerli eserleri bırakan yazıtların sahipleri de ya ticaret yoluyla ya da resmi ziyaretler esnasında Çin aynalarına sahip olmuştur.

Bugüne kadar, tarihî ehemmiyeti üzerinde pek durulmamış olan Yenisey Yazıtları'nın bilhassa Çince yazılı olanları çalışmalarımıza derinlik katacaktır. Bu nedenle Çin para ve ayna yazıtları üzerine daha kapsamlı ve derin çalışmalar yapılması gerekmektedir.

\footnotetext{
${ }^{8}$ Luoyang Müzesi. (1988). Luoyang'da Çıkarılan Bronz Aynalar. Wenwu Basımevi. s. 7.

${ }^{9}$ CONGXIAO, M. (2012). Çin Eski Bronz Ayna Sanatı. Çin Kitabevi. s. 167.

${ }^{10}$ JI, S. (2014). Çin Eski Materyal Kültürü. Zhonghua Kitabevi. s. 348.
} 


\section{Kaynaklar}

CONGXIAO, M. (2012). Çin Eski Bronz Ayna Sanatı. Çin Kitabevi.

HUAITONG, L. ve YUHAO, L. (2010). Çin Bronz Aynaları Tarihi. Zhongzhou Guji Basımevi.

JI, S. (2014). Çin Eski Materyal Kültürü. Zhonghua Kitabevi.

Luoyang Müzesi. (1988). Luoyang'da Çıkarılan Bronz Aynalar. Wenwu Basımevi.

ORKUN, H. N. (2011). Eski Türk Yazıtları. Ankara: Türk Dil Kurumu Yayınları.

YILDIRIM, F., AYDIN, E. ve ALIMOV, R. (2013). Yenisey-Kirgızistan Yazıtları ve Irk Bitig. Ankara: Bilgesu.

YUGUI, W. (1998). Türk Hanlı̆̆ ve Sui-Tang İlişkisi Tarihi Araştırması. Pekin: Çin Sosyal Bilimler Basımevi.

YUKOU, L. (2008). Liezi Tianrui. Zhonghua Kitabevi.

http://bitig.org/?m=2\&oid=63\&mod=1\&tid=2\&lang=k 29.05.2015

http://bitig.org/?m=2\&oid=63\&mod=1\&tid=2\&lang=k 29.05.2015

http://bitig.org/show_big.php?fn=sizes/2580.jpg 03.10.2015 